\title{
Método Analítico para Determinação de Glifosato e AMPA em Amostras Ambientais
}

\author{
Giovanna Amaro Gireli*; Cassiana Carolina Montagner
}

\section{Resumo}

O glifosato é um dos herbicidas mais utilizados em diferentes culturas devido a sua versatilidade. No estado de São Paulo seu destaque é no uso de plantações de cana - de - açúcar, ocorrendo sua rápida conversão no AMPA. Assim, mapear as concentrações presentes no ambiente se torna relevantes. Um método para a determinação de glifosato e AMPA foi desenvolvido baseado otimizando a reação de derivatização com FMOC-Cl, extração em fase sólida (SPE) e extração líquido-líquido (LLE) para posterior análise utilizando cromatografia líquida acoplada com espectrometria de massas (LC-MS/MS). O limite de detecção do método para o glifosato foi de 6,80 $\mu \mathrm{g} / \mathrm{L}$ e para o AMPA de 7,65 $\mu \mathrm{g} / \mathrm{L}$. Análises preliminares em rios da Região Metropolitana de Campinas mostraram concentrações de ambos os analitos abaixo do limite de detecção o qual é cerca de 10 vezes menor que o Valor Máximo Permitido pela legislação nacional.

Palavras-chave: método analítico, contaminantes emergentes, LC-MS/MS

\section{Introdução}

De acordo com o último Boletim de Comercialização de Agrotóxicos e Afins do Ministério do Meio Ambiente (MMA) o glifosato e seus sais foram os ingredientes mais comercializados no Brasil, totalizando 186 mil toneladas em 2012. Como sua aplicação é majoritariamente por pulverização, seu uso pode levar a contaminação de águas superficiais, além disso, possui um potencial carcinogênico para os seres humanos. No ambiente, o glifosato se converte rapidamente no seu principal produto de degradação, AMPA, justificando a necessidade de uma análise simultânea dos dois compostos. Dessa forma, o objetivo geral do trabalho foi desenvolver e validar um método capaz de detectar glifosato e AMPA abaixo das concentrações previstas pela Resolução CONAMA № 357/2005 [1] (65 $\mu \mathrm{g} / \mathrm{L}$ para rios de Classe 1 e $280 \mu \mathrm{g} / \mathrm{L}$ para rios de Classe 3) e testá-lo em uma análise preliminar em rios da Região Metropolitana de Campinas.

\section{Resultados e Discussão}

Inicialmente, o desenvolvimento do método analítico consistiu na otimização do preparo de amostra que envolve uma extração em fase sólida (SPE) para limpeza da amostra, com cartucho Oasis $H L B$, seguido de uma reação de derivatização com $\mathrm{FMOC}-\mathrm{Cl}$ a qual foi melhorada realizando um planejamento fatorial. Após a reação é feito uma última etapa de extração líquido líquido (LLE) com diclorometano para retirada do excesso do FMOC-Cl. Todo esse procedimento foi feito primeiramente em água ultrapura e depois aplicados na matriz, no caso água de rio.

Devido a algumas limitações do método, para a sua validação assumiu-se que a reação de derivatização promove a conversão total dos analitos. Assim, algumas figuras de mérito exigidas pela Resolução RDC №166/2017 da Anvisa [3] não foram feitas, sendo que as figuras de mérito analisadas foram: linearidade da curva de calibração, limite de quantificação (LQ), limite de detecção (LD), efeito matriz e precisão.

A validação do método foi feita direto na matriz, que no caso foi a água do Rio Atibaia em Campinas SP. Com o intuito de minimizar qualquer fonte de erro, o preparo de amostra foi realizado tanto para as amostras quanto para as curvas, na matriz e na água ultrapura.
A curva de calibração foi construída com 5 pontos nas seguintes concentrações: 10, 30, 60, 150 e $300 \mu \mathrm{g} / \mathrm{L}$. A linearidade obtida foi superior a 0,99 para a curva na matriz e na água ultrapura. $O$ efeito matriz foi de 0,54 para o glifosato e 0,65 para o AMPA; LD de 6,80 $\mu \mathrm{g} / \mathrm{L}$ e $7,65 \mu \mathrm{g} / \mathrm{L}$ e LQ de 20,61 $\mu \mathrm{g} / \mathrm{L}$ e 23,19 $\mu \mathrm{g} / \mathrm{L}$ para o glifosato e o AMPA, respectivamente. Em relação aos coeficientes de variação para os três níveis de concentrações avaliados (10,60 e $300 \mu \mathrm{g} / \mathrm{L})$ esses se apresentaram dentro do limite permitido de $20 \%$.

A primeira amostragem realizada, englobou os rios Piracicaba, Corumbataí, Mogi-Mirim, Mogi-Guaçu, Atibaia, Jaguarí, Pirapitingui, Camanducaia e Ribeirões Tijuco-Preto e Tabajara. As análises apontaram concentrações de Glifosato e AMPA abaixo dos limites de detecção dos mesmos, sendo necessário mais amostragens para mapear de forma mais eficiente um cenário de possível contaminação por essas substancias.

\section{Conclusões}

A partir dos dados apresentados, pode-se concluir que o método desenvolvido mostrou-se adequado para a determinação de glifosato e AMPA abaixo das concentrações previstas pelas legislações nacionais. Além disso, sua validação resultou em parâmetros que se encontram de acordo com o permitido pela Resolução da Anvisa [2].

Mesmo com um LD na ordem de $6 \mu \mathrm{g} / \mathrm{L}$ para ambos os analitos, não foi possível detectá-los em uma primeira amostragem indicando que suas concentrações no ambiente se encontram abaixo desse limite.

Por fim, pode-se concluir que mesmo sendo um método satisfatório, para uma quantificação a nível de $\mathrm{ng} / \mathrm{L}$ necessita-se fazer ajustes na metodologia.

\section{Agradecimentos}

FAPESP - Proc. 2015/18790-3

CNPQ pela bolsa concedida

${ }^{1}$ Brasil, Ministério do Meio Ambiente. Resolução CONAMA, No 357 de 17 de Março de 2005.

${ }^{2}$ Brasil, Ministério da Saúde. Resolução da Diretoria Colegiada - RDC N 166 de 24 de Julho de 2017. 